\title{
Regional Myocardial Systolic Function Assessed by Strain Tissue Doppler Imaging in Patients With Isolated Noncompaction of Left Ventricular Myocardium: A Study of Two Cases
}

\author{
Yoshifumi Oishi, MD, Yukio Mizuguchi, MD, Yuko Sawa, MD, Hideji Tanaka, MD, \\ Shigehito Hayashi, MD, Shigefumi Emi, MD, Takeo Ishimoto, MD, \\ Norio Nagase, MD, Kenichi Mori, MD and Takashi Oki, MD \\ Cardiovascular Section, Higashi Tokushima National Hospital, \\ National Hospital Organization, Itano, Japan
}

\begin{abstract}
Isolated noncompaction of the left ventricular myocardium (INVM) is associated with a high incidence of heart failure. However, it is difficult to determine accurately left ventricular (LV) systolic function because of the trabeculated ventricles. The purpose of this study was to clarify whether strain imaging could detect regional myocardial systolic function in 2 patients with INVM. We recorded myocardial strain profiles at the basal, mid-, and apical portions of the LV free wall and ventricular septum (VS) in the apical LV long-axis view. Case 1 (15-year-old male) was referred to our hospital because of ECG abnormalities. Case 2 (83-year-old female) was admitted to our hospital for congestive heart failure. Two-dimensional echocardiography in both patients showed numerous prominent trabeculations and deep intertrabecular recesses at the apex of the LV wall. Because of the trabeculations, it was difficult to determine accurately LV ejection fraction by 2-dimensional echocardiography. The percent fractional shortening of the LV (\%FS) in both cases was within a normal range. However, the peak systolic strains at the apical, mid-, and basal portions of the LV free wall were lower in Case $2(-12,-12$, and $-11 \%$, respectively) than in Case $1(-33,-37$, and $-37 \%$, respectively). The peak systolic strains at the apical, mid-, and basal portions of the VS were also lower in Case $2(-11,-16$, and $-11 \%$, respectively) than in Case $1(-27,-27$, and $-29 \%$, respectively). We conclude that strain measurements are useful for evaluating regional myocardial systolic function in patients with INVM.

(J Echocardiogr 2005; 3: 40-45)
\end{abstract}

Key words: isolated noncompaction of the left ventricular myocardium, strain imaging, regional myocardial systolic function

Noncompacted myocardium has been previously described as the presence of persistent intramyocardial sinusoids. However, the latter is associated with congenital obstructive lesions of the left or right ventricular outflow tract, such as pulmonary atresia with intact ventricular septum [1]. In such patients, regres-

Received December 21, 2004; revision received January 25, 2005; accepted February 18, 2005

Address for correspondence: Yoshifumi Oishi, MD

Cardiovascular Section, Higashi Tokushima National Hospital,

National Hospital Organization,

1-1 Ohmukai-kita, Ohtera, Itano, Itano 779-0193, Japan.

Telephone: +81-88-672-1171

Fax: +81-88-672-3809

E-mail: yoishi@higasitokusima.hosp.go.jp

(C) 2003 Journal of Echocardiography sion of the embryogenic sinusoid is impaired during ontogenesis by ventricular pressure overload, resulting in deep recesses that communicate with both the ventricular cavity and the coronary artery system $[2,3]$.

By contrast, isolated noncompaction of the left ventricular myocardium (INVM) is an idiopathic cardiomyopathy characterized by an altered structure of the myocardial wall as a result of intrauterine arrest of compaction of the myocardial fibers in the absence of any coexisting congenital lesion [4]. There is continuity between the left ventricular (LV) cavity and the deep intertrabecular recesses that are filled with blood from the ventricular cavity without evidence of communication to the epicardial coronary artery system $[5,6]$.

The clinical manifestations of INVM include LV 
heart failure, systemic arterial embolism, and severe arrhythmias in some pediatric patients [5, 7]. Early diagnosis by routine echocardiography is important because of the high incidence of heart failure. However, it is difficult to determine accurately the LV ejection fraction by 2-dimensional echocardiography due to the presence of trabeculated ventricles [8]. Recent advances in 2-dimensional color-coded tissue Doppler imaging have enabled the measurement of regional myocardial strain $[9,10]$.

The purpose of the present study was to determine whether strain imaging could accurately evaluate regional myocardial systolic function compared to global LV pump function determined by M-mode and 2-dimensional echocardiography in 2 patients with INVM.

All ultrasound examinations were performed with a commercial ultrasound system (Power Vision 8000, Toshiba Corp, Tokyo, Japan). The thicknesses of the ventricular septum (VS) and LV posterior wall and the LV end-diastolic and end-systolic diameters (Dd and Ds, respectively) were determined from the M-mode echocardiograms acquired at the level of the chordae tendineae. The percent LV fractional shortening (\%FS) was calculated by the following formula:

$$
\text { FS }(\%)=[(\mathrm{Dd}-\mathrm{Ds}) / \mathrm{Dd}] \times 100 .
$$

The mitral annular motion velocity was recorded using the pulsed Doppler method in the apical LV long-axis view with a $3.75-\mathrm{MHz}$ probe, and the peak systolic mitral annular motion velocity ( $\mathrm{Sw}$ ) was determined. The acoustic power and filter frequencies of the ultrasound system were set to the lowest values possible, and the sample volumes (width of approximately $8 \mathrm{~mm}$ ) were set at the mitral annulus of the LV posterior wall (PW).

Strain imaging data were collected from a transthoracic approach using the same system equipped with a 2.5-MHz transducer and were acquired at a frame rate of 68 frames/sec and a sector angle of 30 degrees. The apical LV long-axis view and 4-chamber view were used to investigate apical, mid-, and basal portions of the LV PW and VS, respectively. During the acquisition, the pulse-repetition frequency was adjusted to avoid aliasing. The heart cycles were recorded during brief breath-holding and were digitally stored off-line using custom software (ApliQ ver. 1.3, Toshiba Corp). Segmental systolic strain curves were derived from the off-line analysis of color Doppler myocardial image clips, and the peak values were determined.

\section{Case Report}

\section{Case 1}

A 15-year-old male was referred to our hospital for evaluation because of ECG abnormalities. He had no symptoms, ventricular arrhythmias, or systemic embolic episodes. There was no family history of cardiomyopathy or sudden death. Pulse rate was $60 / \mathrm{min}$; blood pressure was $120 / 60 \mathrm{~mm} \mathrm{Hg}$. There were no additional heart sounds or significant murmurs. Electrocardiography revealed coronary sinus rhythm, ST depressions in leads II, III and aVF, and inverted $\mathrm{T}$ waves in leads II, III, aVF and $\mathrm{V}_{2-4}$.

The 2-dimensional echocardiogram showed numerous prominent trabeculations and deep intertrabecular recesses in the apex of the LV wall (Figure 1, top). However, no abnormalities of apical wall motion was noted. The Dd and Ds were $4.4 \mathrm{~cm}$ and $2.6 \mathrm{~cm}$, respectively, and the $\% \mathrm{FS}$ was $41 \%$ (Figure 2, left). The transmitral flow velocity revealed a normal pattern, with a ratio of early to late diastolic peak velocity (E/A) of 2.9.

\section{Case 2}

An 83-year-old female was admitted to our hospital for congestive heart failure. There was no family history of cardiomyopathy or sudden death. Pulse rate was $84 / \mathrm{min}$; blood pressure was $140 / 82 \mathrm{~mm} \mathrm{Hg}$. There were no additional heart sounds or significant murmurs. Electrocardiography revealed sinus rhythm and ST depressions and inverted $\mathrm{T}$ waves in leads $\mathrm{I}, \mathrm{aVL}$ and $\mathrm{V}_{5,6}$. The 2-dimensional echocardiogram showed numerous prominent trabeculations and deep intertrabecular recesses in the apex of the LV wall (Figure 1, bottom). The transmitral flow velocity revealed an abnormal relaxation pattern, that is, the E/A was 0.6. The Dd and Ds were $5.4 \mathrm{~cm}$ and $3.4 \mathrm{~cm}$, respectively. The $\% \mathrm{FS}$ was $36 \%$ (Figure 2, right), although the apical LV wall was hypokinetic.

Based on pulsed tissue velocity imaging, the peak systolic mitral annular motion velocity was lower in Case 2 than in Case 1 ( 8.9 and $15.2 \mathrm{~cm} / \mathrm{s}$, respectively) (Figure 3). The apical, mid-, and basal peak systolic strains of the LV free wall were lower in Case $2(-12$, -12 , and $-11 \%$, respectively) than in Case $1(-33,-37$, and $-37 \%$, respectively) (Figure 4, top). The apical, mid-, and basal peak systolic strains of the VS were also lower in Case $2(-11,-16$, and $-11 \%$, respectively) than in Case 1 (-27, -27, and -29\%, respectively) (Figure 4, bottom). 


\section{Case 1}

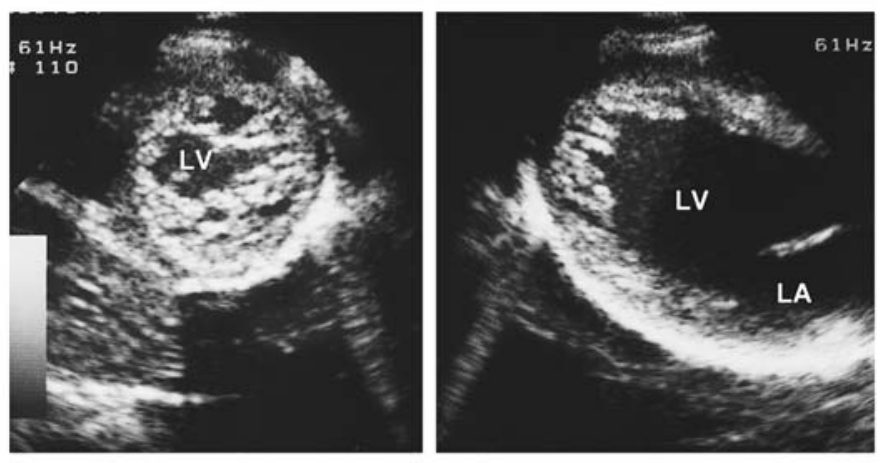

Case 2

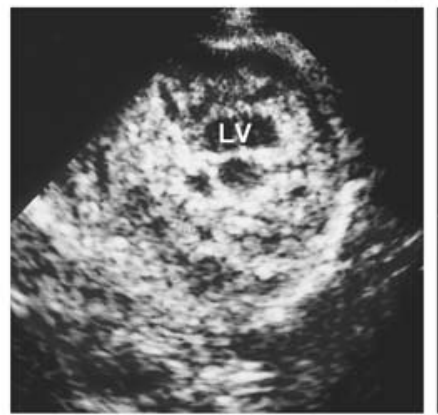

Short-axis

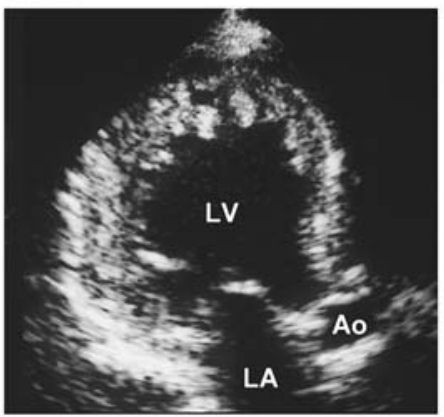

Long-axis

Fig. 1. Two-dimensional short-axis at the left ventricular (LV) apical wall level and LV long-axis echocardiography in 2 cases. Numerous prominent trabeculations and deep intertrabecular recesses are observed in the apex of the LV wall in Case 1 and Case 2. LV, left ventricle; LA, left atrium; Ao, aorta.

\section{Case 1}

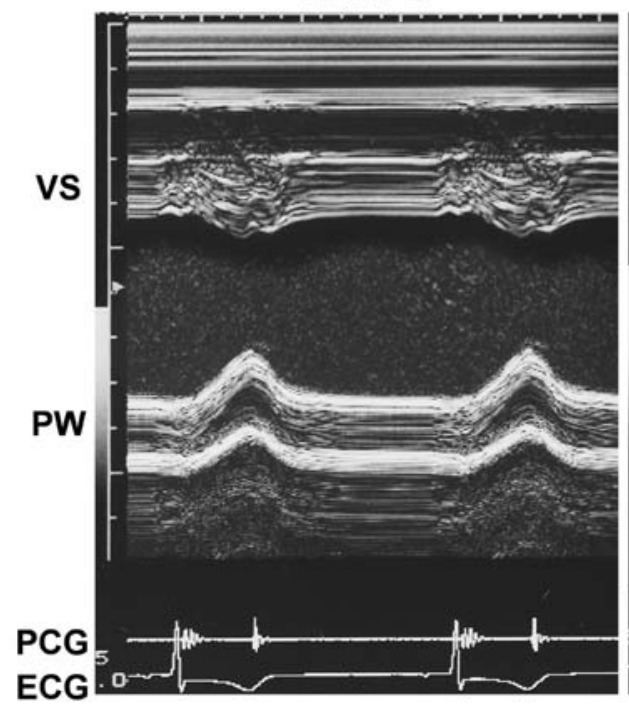

\section{Case 2}

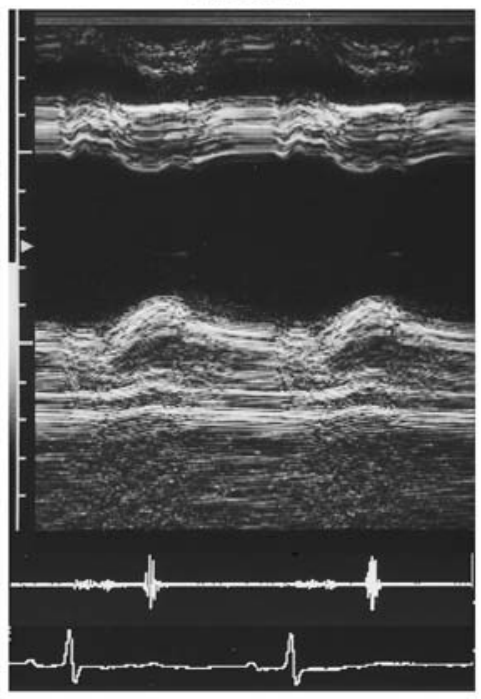

Fig. 2. M-mode echocardiography in 2 cases. The percent fractional shortening of the left ventricle was $41 \%$ in Case 1 and $36 \%$ in Case 2. VS, ventricular septum; PW, left ventricular posterior wall; ECG, electrocardiogram; PCG, phonocardiogram. 
Case 1

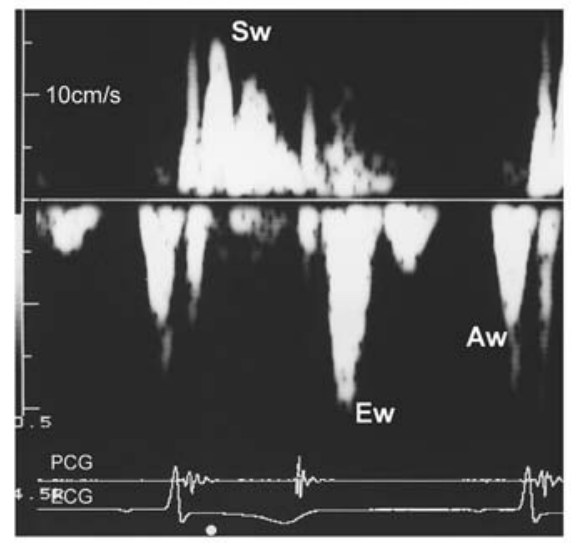

Case 2

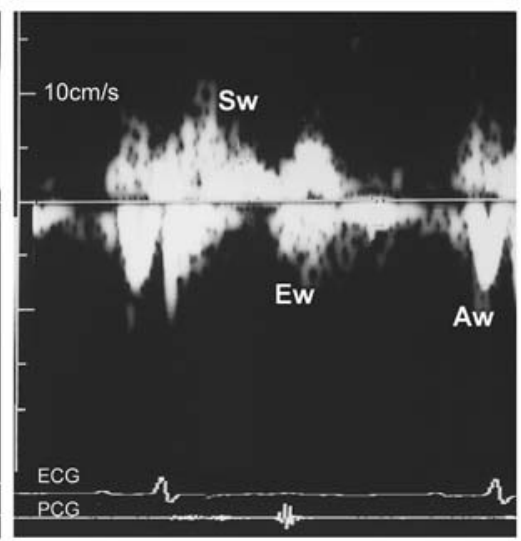

Fig. 3. Tissue velocity imaging of the mitral annulus in 2 cases. The peak systolic mitral annular motion velocity (Sw) is lower in Case $2(8.9 \mathrm{~cm} / \mathrm{s})$ compared to Case $1(15.2 \mathrm{~cm} / \mathrm{s})$. Ew, peak early diastolic motion velocity; Aw, peak atrial systolic motion velocity; ECG, electrocardiogram; PCG, phonocardiogram.

Case 1
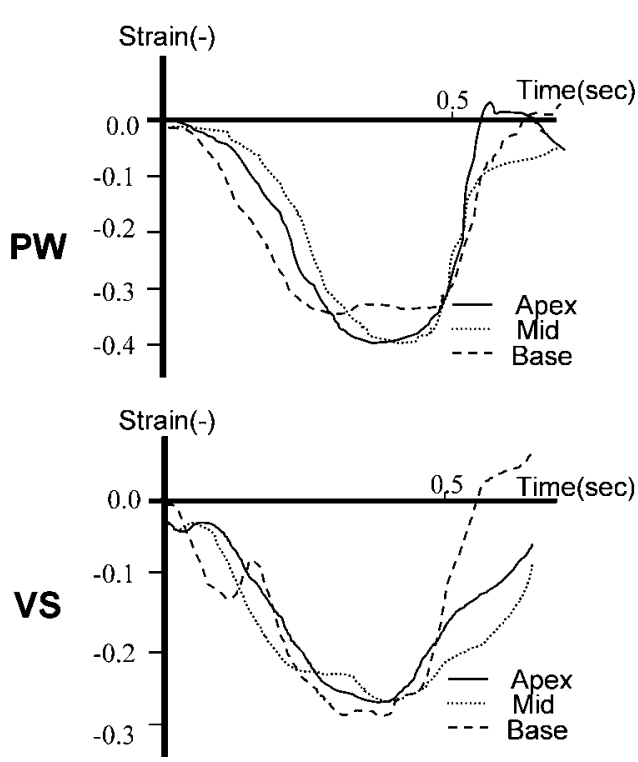

Case 2
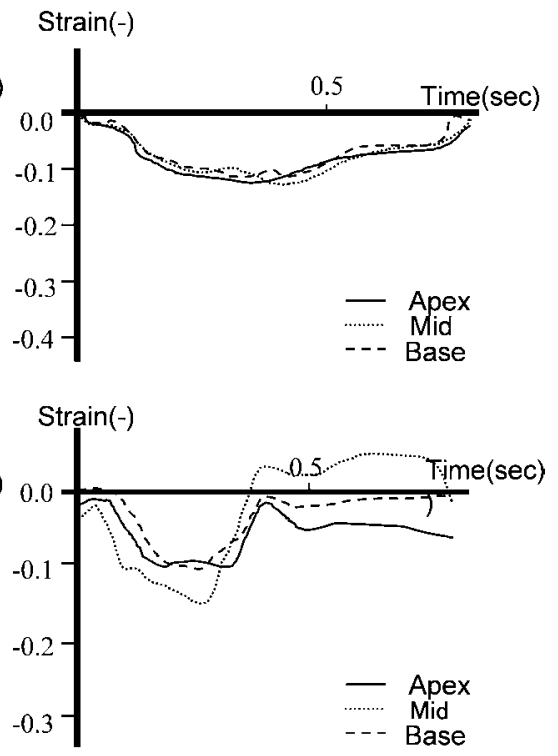

Fig. 4. Myocardial strain profiles from the left ventricular posterior wall (PW) and ventricular septum (VS) in 2 cases. The apical, mid- and basal peak systolic strains of the PW and VS are lower in Case 2 than in Case 1.

\section{Discussion}

The following findings are important as echocardiographic features of INVM: 1) multiple prominent ventricular trabeculations, 2) multiple deep intertrabecular recesses communicating with the ventricular cavity, 3 ) dilated ventricles, and 4) depressed systolic and diastolic function [11]. In particular, myocardial trabeculations are most prominent in the apical and middle portions of the ventricles [11]. Because of the high incidence of heart failure, early diagnosis of this cardiac disorder using routine echocardiography is important. 
Ichida et al. [7] reported that global systolic function in patients with INVM is depressed in many cases, whereas the regional systolic function is well preserved at the chordae tendineae or papillary muscle level. Based on the fact, which INVM is most prominent in the apical portion of the LV, evaluation of $\mathrm{LV}$ systolic pump function determined by M-mode echocardiography may be overestimated in patients with INVM. Actually, the \%FS values in both cases were within a normal range in the present study. Furthermore, the trabeculated ventricles make 2dimensional echocardiographic analysis unreliable [8].

Traditionally, cardiac ultrasound has quantified regional myocardial function by combining visual analysis of wall motion with the measurement of wall thickening and thinning. The measurement of regional myocardial strain index by color-coded tissue Doppler imaging has recently been proposed as a possible alternative because experimental studies have confirmed that changes in segmental myocardial systolic deformation are closely linked to changes in contractility in the normal myocardium [12]. The strain imaging reflects differing aspects of myocardial deformation and is relatively independent of entire heart motion [13-15]. Therefore, this new modality should be expected to give a more sensitive assessment of regional myocardial function.

Based on our findings, tissue velocity analysis of the longitudinal direction by pulsed tissue velocity imaging was useful for a symptomatic patient with INVM. However, the longitudinal myocardial contractility in early systole is impaired with increased age, even in healthy individuals [16]. Recently, Sun et al. [17] demonstrated that the myocardial velocities and strain rate showed a significant dependence on age, whereas displacement and peak systolic strain measures were less affected. Edvardsen et al. [18] found that longitudinal myocardial Doppler velocities decreased progressively from the base to the apex of the LV wall, whereas myocardial strain rates and strains were uniform in all segments. Therefore, longitudinal myocardial function assessed by peak systolic strain measurements is reliable, even in elderly patients.

In patients with cardiac amyloidosis, it has also been reported that $\mathrm{LV}$ contraction abnormalities determined by strain imaging precedes the onset of congestive heart failure and can be detected by strain but is not apparent by tissue velocity imaging [19].

Recently, Hasegawa et al. [20] reported that mean peak strain values of normokinetic wall segments were $-20 \pm 5.5 \%$ in the longitudinal direction. In the present study, strain values in case 1 were preserved, but those in case 2 were decreased. However, there was no significant difference in the $\% \mathrm{FS}$ between both cases. Therefore, the tissue velocity and strain imaging methods are useful for evaluating longitudinal LV contractility in patients with INVM. Specifically, strain imaging may be able to detect accurately abnormalities in longitudinal myocardial systolic function compared to conventional M-mode and 2-dimensional echocardiography in patients with INVM.

\section{References}

1. Lauer RM, Fink HP, Petry EL, Dunn MI, Diehl AM. Angiographic demonstration of intramyocardial sinusoids in pulmonary-valve atresia with intact ventricular septum and hypoplastic right ventricle. N Engl J Med 1964; 271 : 68-72.

2. Dusek J, Ostadal B, Duskova M. Postnatal persistence of spongy myocardium with embryonic blood supply. Arch Pathol 1975; 99: 312-7.

3. Freedom RM, Patel RG, Bloom KR, et al. Congenital absence of the pulmonary valve associated with imperforate membrane type of tricuspid atresia, right ventricular tensor apparatus and intact ventricular septum: a curious developmental complex. Eur J Cardiol 1979; 10: 171-96.

4. Jenni R, Goebel N, Tartini R, Schneider J, Arbenz U, Oelz O. Persisting myocardial sinusoids of both ventricles as an isolated anomaly: echocardiographic, angiographic, and pathologic anatomical findings. Cardiovasc Intervent Radiol 1986; 9: 127-31.

5. Chin TK, Perloff JK, Williams RG, Jue K, Mohrmann R. Isolated noncompaction of left ventricular myocardium. A study of eight cases. Circulation 1990; 82: 507-13.

6. Ritter M, Oechslin E, Sutsch G, Attenhofer C, Schneider $\mathrm{J}$, Jenni R. Isolated noncompaction of the myocardium in adults. Mayo Clin Proc 1997; 72: 26-31.

7. Ichida F, Hamamichi Y, Miyawaki T, et al. Clinical features of isolated noncompaction of the ventricular myocardium: long-term clinical course, hemodynamic properties, and genetic background. J Am Coll Cardiol 1999; 34: 233-40.

8. Finsterer J, Stöllberger C, Blazek G. Left ventricular noncompaction suggests myopathy. Circulation 2004 109: e201-2; author reply e201-2.

9. Sutherland GR, Stewart MJ, Groundstroem KW, et al. Color Doppler myocardial imaging: a new technique for the assessment of myocardial function. J Am Soc Echocardiogr 1994; 7: 441-58.

10. Oki T. The role of tissue Doppler imaging as a new diag- 
nostic option in evaluating left ventricular function. J Echocardiogr 2003; 1: 29-42.

11. Alizad A, Seward JB. Echocardiographic features of genetic diseases: part 1. Cardiomyopathy. J Am Soc Echocardiogr 2000; 13: 73-86.

12. Weidemann F, Jamal F, Sutherland GR, et al. Myocardial function defined by strain rate and strain during alterations in inotropic states and heart rate. Am J Physiol 2002; 283: H792-9.

13. Sutherland GR, Di Salvo G, Claus P, D'hooge J, Bijnens B. Strain and strain rate imaging: a new clinical approach to quantifying regional myocardial function. J Am Soc Echocardiogr 2004; 17: 788-802.

14. Urheim S, Edvardsen T, Torp H, Angelsen B, Smiseth OA. Myocardial strain by Doppler echocardiography. Validation of a new method to quantify regional myocardial function. Circulation 2000; 102: 1158-64.

15. Edvardsen T, Skulstad H, Aakhus S, Urheim S, Ihlen H. Regional myocardial systolic function during acute myocardial ischemia assessed by strain Doppler echocardiography. J Am Coll Cardiol 2001; 37: 726-30.

16. Onose Y, Oki T, Mishiro Y, et al. Influence of aging on systolic left ventricular wall motion velocities along the long and short axes in clinically normal patients determined by pulsed tissue Doppler imaging. J Am Soc Echocardiogr 1999; 12: 921-6.

17. Sun JP, Popovic ZB, Greenberg NL, et al. Noninvasive quantification of regional myocardial function using Doppler-derived velocity, displacement, strain rate, and strain in healthy volunteers: effects of aging. J Am Soc Echocardiogr 2004; 17: 132-8.

18. Edvardsen T, Gerber BL, Garot J, Bluemke DA, Lima JA, Smiseth OA. Quantitative assessment of intrinsic regional myocardial deformation by Doppler strain rate echocardiography in humans: validation against three-dimensional tagged magnetic resonance imaging. Circulation 2002; 106: 50-6.

19. Koyama J, Ray-Sequin PA, Falk RH. Longitudinal myocardial function assessed by tissue velocity, strain, and strain rate tissue Doppler echocardiography in patients with $\mathrm{AL}$ (primary) cardiac amyloidosis. Circulation 2003; 107: 2446-52.

20. Hasegawa T, Nakatani S, Maruo T, et al. Quantitative assessment of wall motion using myocardial strain. J Echocardiogr 2003; 1: 23-8. 